\title{
Implementation of High frequency SVM in a Digital System for CS-SiC Inverter .
}

\author{
E. Fernández, A. Paredes V. Sala, L. Romeral \\ ${ }^{1}$ Department of Electronics Engineering \\ Technical University of Catalonia. MCIA \\ Campus of Terrassa - Barcelona, 08222 Terrassa (Spain) \\ Phone: +0034 652028756, e-mail efren.fernandez@mcia.upc.edu
}

\begin{abstract}
The operation of current source inverters at high frequency allows to reduce the size of the input coil and output filters. These advantages allowed to obtain converters with better performance and to reduce the size and weight of the passives elements, decreasing the manufacturing costs and while keeping the current harmonic distortion low. For these reasons, it is necessary to implement a modulation technique that allows the converter to work at a higher frequency $100 \mathrm{KHz}$.

This article presents the design and implementation of a Space Vector Modulation (SVM) technique for high switching frequencies for a Current Source Inverter (CSI) topology implemented with $\mathrm{SiC}$ devices. The technique is programmed and implemented in a PIC 24FJ256GA406 microcontroller, for the activation and control of $\mathrm{SiC}$ devices in each leg of power converter.
\end{abstract}

\section{Key words}

Space Vector Modulation, High Frequency, Current Source Inverter, Silicon Carbide, Microcontroller.

\section{Introduction}

Nowadays there has been an increase in research of power electronics with bandgap elements for the development of power converters with different topologies and the trend keeps growing. Recent research [1-2] determined that silicon carbide is a very promising electronic material especially when used in the manufacturing of semiconductor devices, having higher operating temperature ranges, supporting higher power and higher switching frequencies when compared to conventional silicon elements with operation characteristics below these elements (Fig. 1).

By considering these advantages of $\mathrm{SiC}$ devices which can counteract the different operation problems at high frequency, temperature and power loss of conventional VSI and CSI topologies, this paper proposes a space vector modulation (SVM) at high frequency of activation for a CSI topology developed with silicon carbide devices that will be implemented and programmed in a PIC microcontroller. The CSI topology is considered ideal when operating at high frequency [3-4], considering that the input inductor of the power converter would be smaller as well as the filter capacitors and the $\mathrm{SiC}$ semiconductors offering a high blocking voltage and a low resistance state.

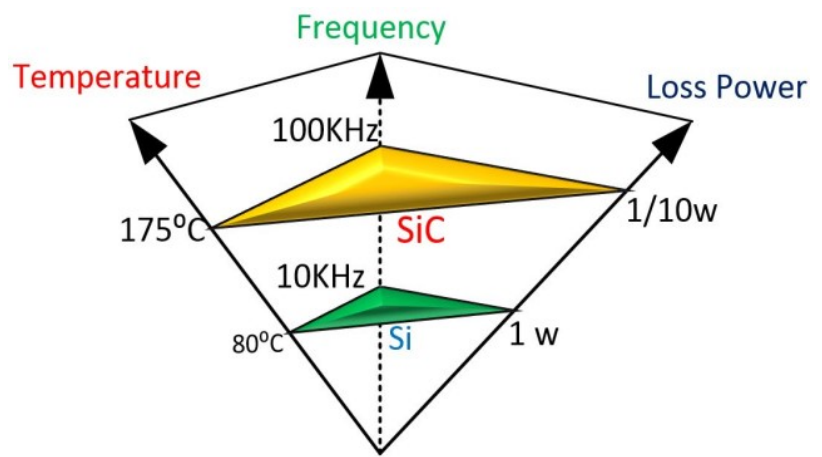

Fig. 1 Features of $\mathrm{SiC}$ vs Si.

The proposed article contributes to the implementation of digital control systems using modulation techniques for CSI topologies with $\mathrm{SiC}$ devices. The use of this technology will allow to reduce the size and weight of the coil in the CSI topology and to get more compact and efficient systems. Furthermore, the development of this technique modulation at high frequency will allow to decrease the harmonics and to reduce power losses in the converter.

The article is organized into the following sections. Section II presents a brief review of the different modulation methods for CSI inverters. Section III describes the development of the modulation technique implemented in the digital system. Section IV present the simulation results, as well as the experimental validation and analysis of the weight of coils used. Finally the conclusions are presented in Section V.

\section{Techniques of Modulation for CSI}

\section{a) Selective Harmonic Elimination (SHE)}

SHE is an offline strategy based on obtaining angles that enable the on-off switching of the static converter devices (Fig.2), both inverter topologies voltage source and current source, with the purpose of obtain a content lower 
current harmonic [5]. The advantages of this type of modulation are the obtaining of lower switching losses and the removal of a large number of harmonics, reducing the size of DC converters filter. [6] One problem with this technique is that the amplitude modulation index $\mathrm{m}$ has a narrow operating range, which cause not to have adequate control over the amplitude of the voltage or current [6].

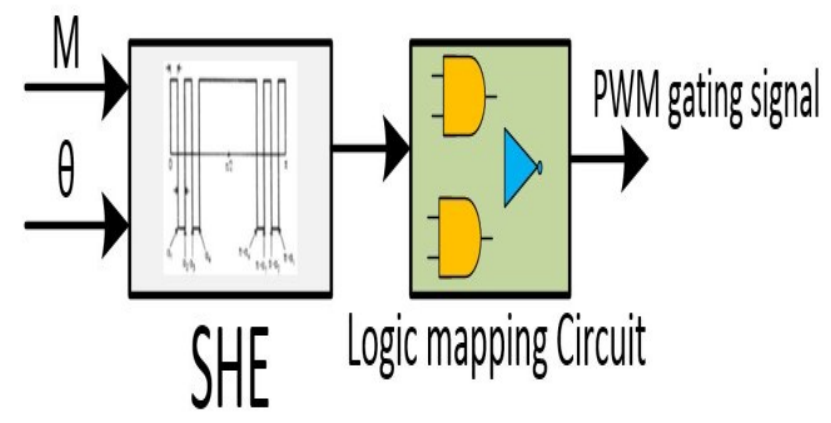

Fig 2. Selective harmonic elimination SHE.

\section{b) Carrier based Sinusoidal PWM (CSPWM)}

This is the technique with the best performance when applied to CSI. It can be performed directly from the space vector diagram dedicated to CSI (Fig 4). This technique is suitable for applications that use high switching frequency [7].

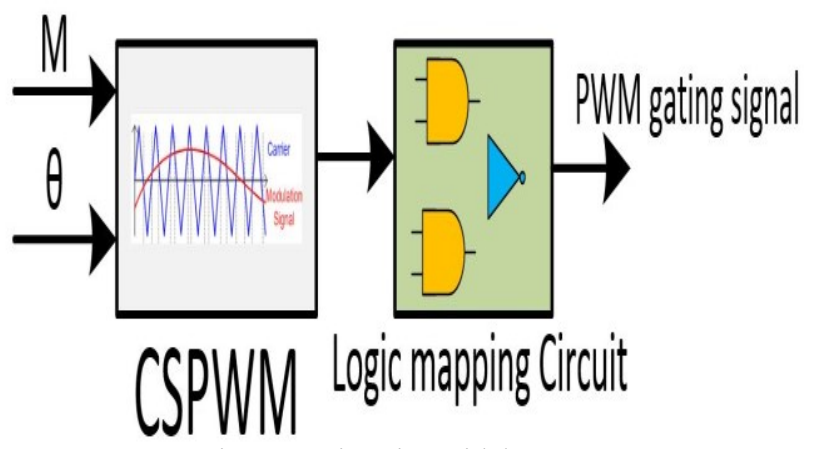

Fig 3. Carrier Sinusoidal PWM.

\section{c) Space Vector Modulation (SVM)}

This technique can be used in the CSI topology, can be performed directly from the space vector diagram dedicated to CSI (Fig 4), this technique are suitable for applications that use a high switching frequency.

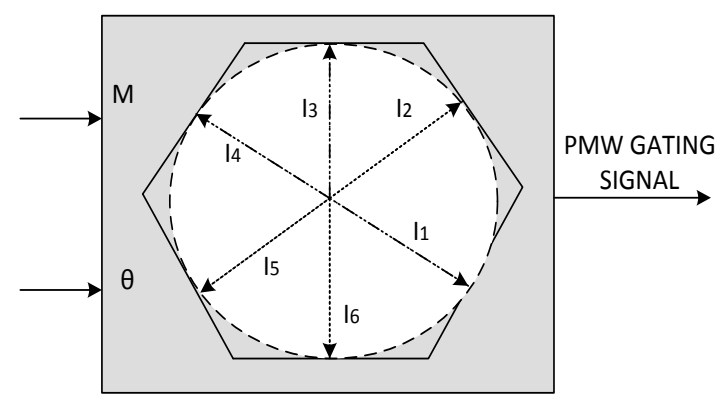

Fig.4. Space Vector Modulation SVM.

\section{Technique Modulation to High Frequency.}

In the current source inverter, the modulation technique is responsible of generating the $\mathrm{AC}$ output signal waveform, its current level and frequency [8]. The SVM technique for CSI bridge inverter is handled by nine switching states [9] and is considered the best alternative for power converters due to the low harmonic content and minimized switching losses. The topology CSI with SiC devices is shown in the Fig.5.

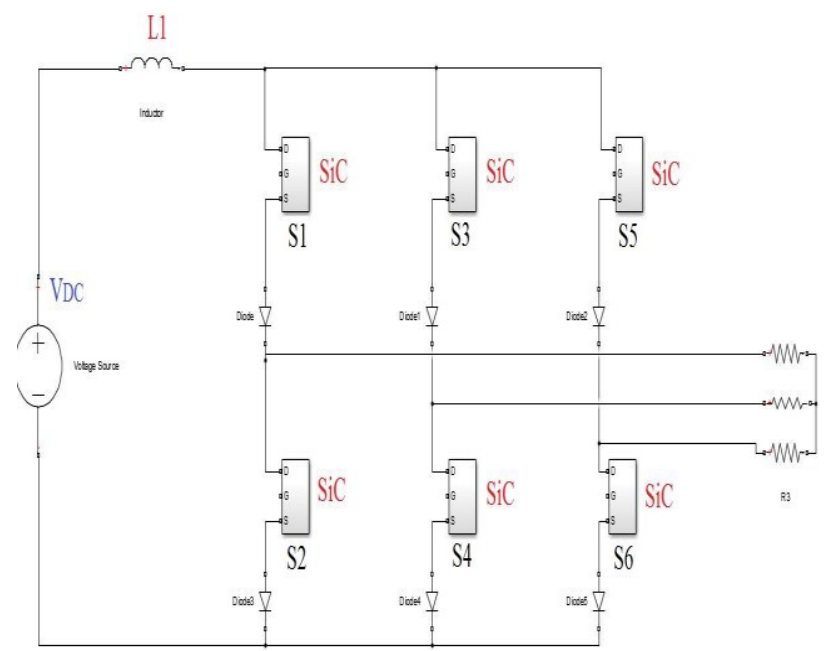

Fig.5. Topology CSI with $\mathrm{SiC}$ devices.

In the Figure $6 a$, the vectors of current I1-I6 called actives states and vector null I7, 8, 9 are identified, the actives states form a hexagon divided into six equal sectors and zero vectors are in the center of the hexagon [5]. The reference vector is given by a phase of the power converter and can be written:

$$
\begin{gathered}
I_{r e f}=\frac{2}{3}\left(i_{w a}+i_{w b} e^{\frac{2 \pi}{3} j}+i_{w c} e^{\frac{4 \pi}{3} j}\right) \\
I_{r e f}=I_{r e f \alpha}+I_{r e f \beta}=\left|I_{r e f}\right| e^{j \theta}
\end{gathered}
$$

Where Iref $\alpha$ and Iref $\beta$ is the length of the axes $\alpha$ and $\beta$ of the complex plane Fig. $6 b$.

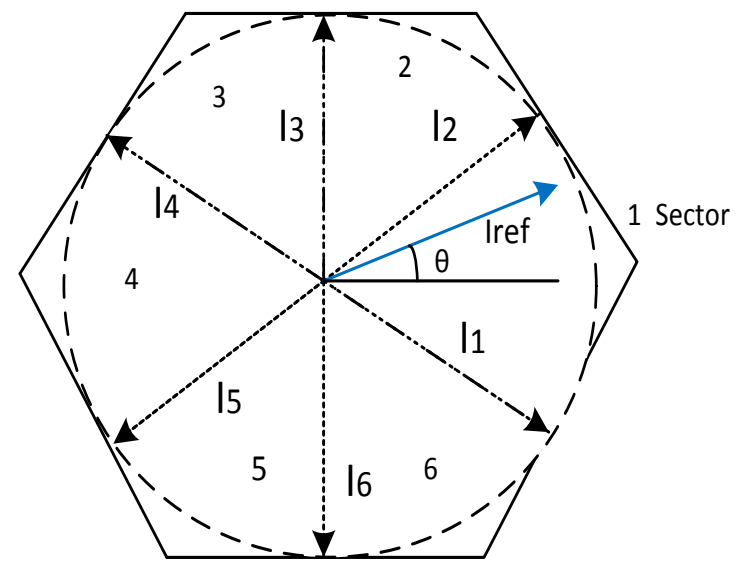

Fig.6. Vectors of current for SVM, Iref.

Furthermore, three reference currents can be generated: IA, IB, IC, and with them id and iq can be calculated using the following expression: 


$$
\left(\begin{array}{l}
i_{d} \\
i_{q}
\end{array}\right)=\frac{2}{3}\left[\begin{array}{ccc}
1 & -\frac{1}{2} & -\frac{1}{2} \\
0 & \frac{\sqrt{3}}{2} & \frac{-\sqrt{3}}{2}
\end{array}\right]
$$

This transformation can be used to associate the three reference currents with a three-phase CSI with the purpose of obtaining Iref and $\theta$ with the following expressions:

$i_{r e f}=\sqrt{i_{q}+i_{d}}$

$\theta=\operatorname{arcotang} \frac{i_{q}}{i_{d}}$

The technique of SVM approximated the reference vector Iref, using the nine vectors, when the vector Iref is between two vectors IK IK +1 , and when these are combined with one I7, 8, 9 vectors null form the vector Iref.

$$
I_{K}=\left\{\begin{array}{cl}
\frac{2}{\sqrt{3}} I_{D C} e^{j(k-1)\left(\frac{\pi}{3}-\frac{\pi}{6}\right)} & k=1 \ldots 6 \\
0 & k=1 \ldots 6
\end{array}\right.
$$

The generation of vector current in a sampling period Ts, will depend on the sampling frequency (in our case $100 \mathrm{KHz}$ ), and combined with the currents supplied by $\mathrm{I}_{\mathrm{K}}$, $\mathrm{I}_{\mathrm{K}+1}$ vectors, $\mathrm{I}_{\mathrm{Z}}$ used during times $\mathrm{T}_{1}, \mathrm{~T}_{2}$ and $\mathrm{Tz}[10]$ and are approaching a value equal to the reference vector Iref. The dwell time can be obtained by:

$$
\begin{aligned}
& T_{1}=m T_{s} \operatorname{Sin}\left(\frac{\pi}{6}-\theta+(n+1) \frac{\pi}{6}\right. \\
& T_{1}=m T_{s} \operatorname{Sin}\left(\frac{\pi}{6}-\theta-(n+1) \frac{\pi}{6}\right. \\
& T_{z}=T_{s}-T_{1}-T_{2}
\end{aligned}
$$

Where $\mathrm{m}$ is the modulation index and $\mathrm{n}$ is the sector number.

$m=\frac{i_{r e f}}{I_{D C}}$

The activation sequence of each device has a PWM pattern for CSI, which must satisfy the following constraint, only two switches can be enabled in each time instant: one in the upper half of the CSI bridge and the other in the bottom half. For the selection of a trigger sequence, the sampling time Ts is divided in three time segments in function of the driving of each activation for forming the vectors, the times and activation sequences for the six sectors are shown in Fig. 7.
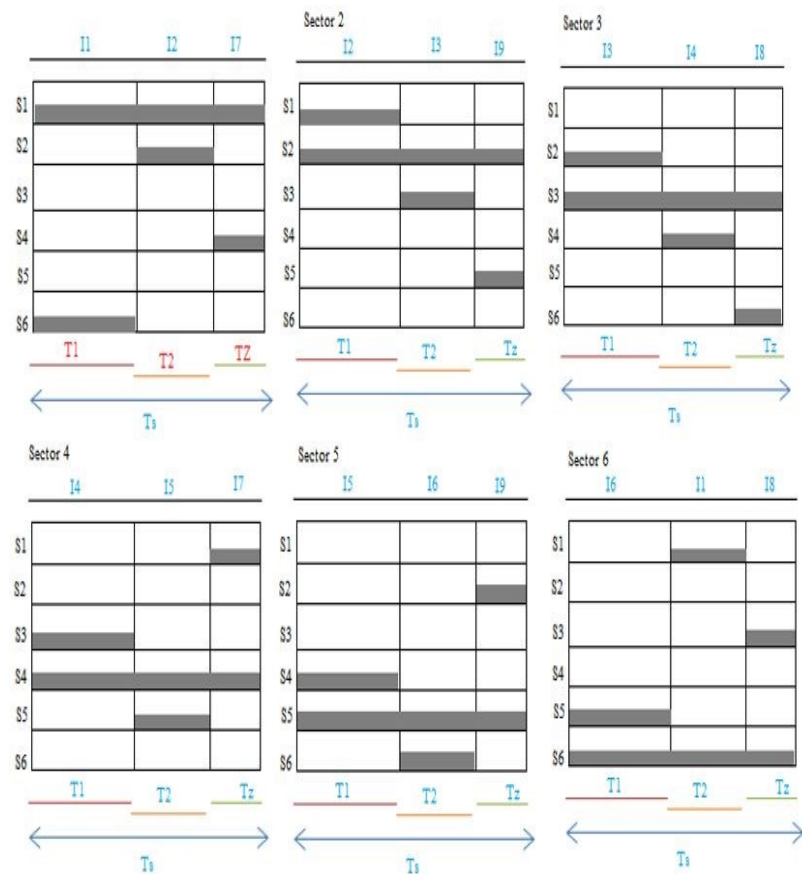

Fig.7. Activating sequence used for modulation.

\section{Simulations and Results}

This section presents the results obtained during the simulation and experimental validation of the proposed technique. The analysis is implemented on a CSI topology with $\mathrm{SiC}$ devices and control drives for each $\mathrm{SiC}$ transistor gate (Fig.8). The characteristics of the power converter are, $\mathrm{VDC}=25 \mathrm{~V}$, Linput $=50 \mathrm{uH}$ and $100 \mathrm{uH} 5 \mathrm{~A}$ of DC Link current and $5 \Omega$ loads on each phase. The SiC devices are the SCT2450KEC from manufacturer ROHM and Schottky diode C3D08060A from manufacturer CREE. The characteristics of these device are VDDS $=1200 \mathrm{~V}$; $\mathrm{ID}=10 \mathrm{~A} ; \mathrm{Rds}=450 \mathrm{~m} \Omega$ and fast switching speed and for diode Schottky VRRM=600V, If $=11 \mathrm{~A}$.

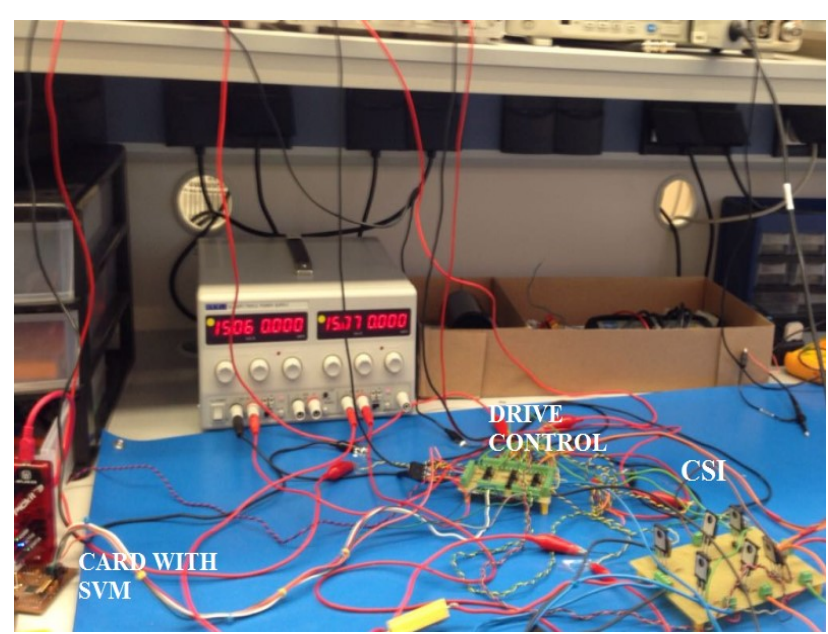

Fig.8.CSI Topology and Control System with SVM proposed.

The modulation is implemented in Matlab- Simulink. The different equations were implemented as embedded Matlab function blocks, each block represents a function. The equation blocks are presented in the Fig 9. 


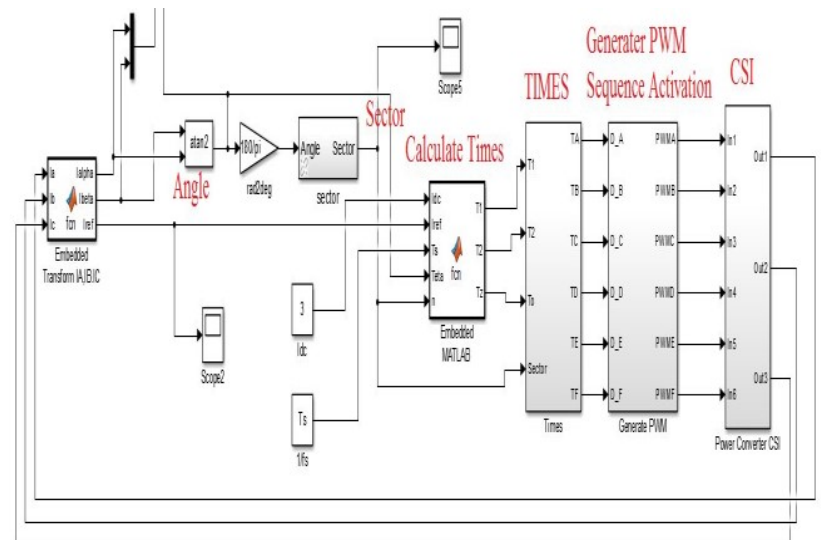

Fig.9.Implementation of SVM at high frequency in Simulink Matlab.

For validating the results obtained in Matlab, an electronic board prototype was built (Fig.10) where the SVM modulation technique was implemented. The technique was programmed in C language in a PIC24FJ256GA406. This microcontroller has several PWM outputs that can be configured at different frequency levels.

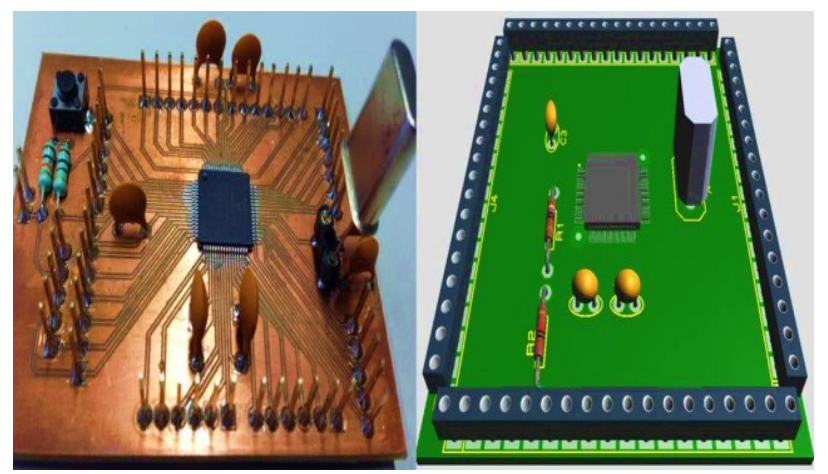

Fig.10.Implementation of electronic board with PIC24FJ256GA406 microcontroller.

Fig.11 shows, the different coils used to test the size reduction of the passive element in the CSI.

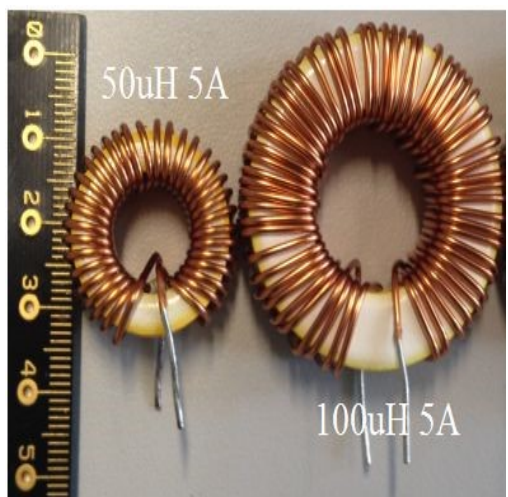

Fig.11. Size of coils used in the CSI power converter.

Fig. 12 shows the results of the simulation of the proposed modulation technique in Matlab-Simulink.
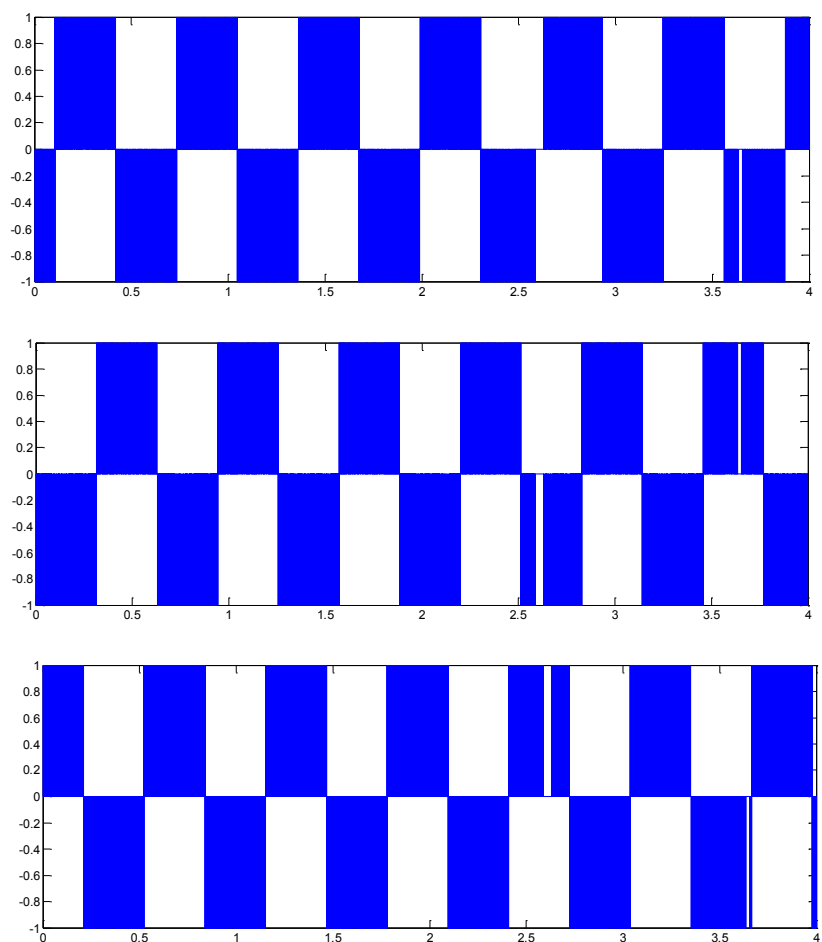

Fig.12. Output currents in Simulation.

The results of experimental validation are shown in Fig. 13. First, the drive signals for the converter are presented; these signals match the proposed signals shown in Fig. 7.

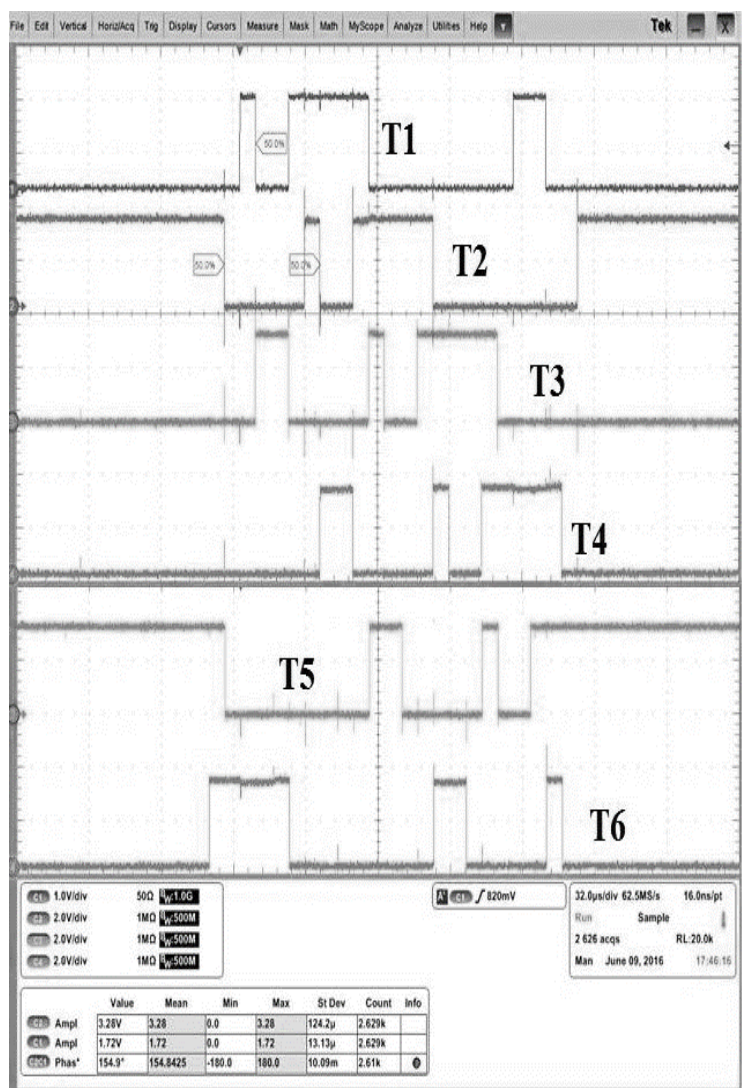

Fig.13. Drive Signals obtained in the system digital.

In the second part, the phase currents obtained in the CSI power converter are shown in the Fig. 14. 


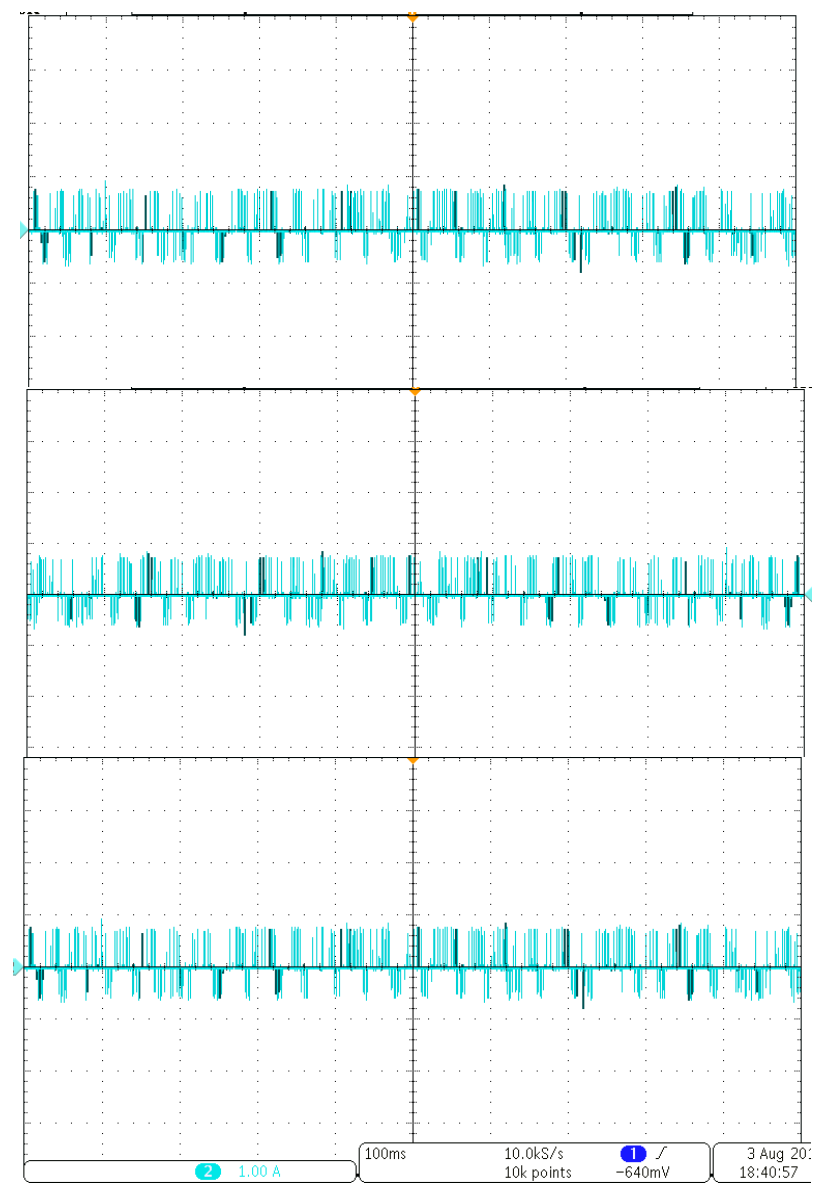

Fig. 14. Current of out in CSI SiC Power Converter.

In the Fig. 15 the comparative analysis between the different types of coils used in the experimental validation in function of weight and percent are presented. The $100 \mathrm{uH}$ coil accounts for $56 \%$ of weight of the inverter while the $50 \mathrm{uH}$ coil accounts for $44 \%$ of weight of the inverter.

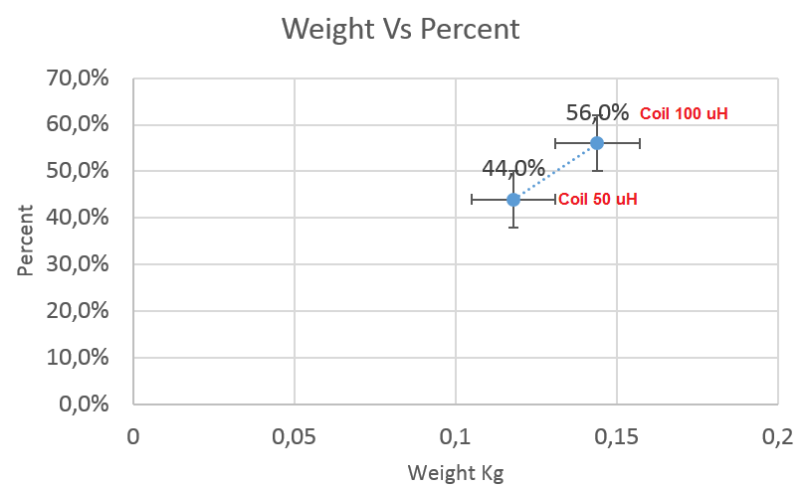

Fig.15. Analisys comparative of coils of input.

\section{Conclusions}

This paper presents the implementation of a high frequency SVM in a digital system. The application is development in a PIC microcontroller that controls the switching of $\mathrm{SiC}$ devices. The proposed method and sequence was implemented in an electronic board with PIC 24FJ256GA406 microcontroller.

The objective of the proposal is to work at high frequency of operation in order to reduce the size of the input coil in the CSI. The results obtained in the simulations and experimental validation confirm that the technical proposal is adequate for its implementation and that the reduction of the size of the input coil is possible.

The implementation of modulation techniques in digital systems is considered very useful. This allows the implementation of hardware in the loop systems that are able to optimize for different applications and to minimize the design.

The output current signals presents discontinuities which is due to the lack of constant DC link in the power converter. This effect is by the lack of control in the current source. A control stage can be implemented in the future.

The implementation of these topologies with $\mathrm{SiC}$ devices provide several advantages such as very high frequency of operation, reduction of the power losses, volume and weight of passive devices, as well as the improvement of the performance.

\section{ACKNOWLEDGMENT}

This work was supported in part by the Spanish Ministry of Economy and Competitiveness under the TRA201680472-R Research Project.

\section{REFERENCES}

[1] Fei Shang; Arribas, A.P.; Krishnamurthy, M., "A comprehensive evaluatiol6n of $\mathrm{SiC}$ devices in traction applications," in Transportation Electrification Conference and Expo (ITEC), 2014 IEEE , vol., no., pp.1-5, 15-18 June 2014.

[2] Jahdi, S.; Alatise, O.; Fisher, C.; Li Ran; Mawby, P., "An Evaluation of Silicon Carbide Unipolar Technologies for Electric Vehicle Drive-Trains," in Emerging and Selected Topics in Power Electronics, IEEE Journal of , vol.2, no.3, pp.517-528, Sept. 2014.

[3] Hak-Jun Lee; Sungho Jung; Seung-Ki Sul, "A Current Controller Design for Current Source Inverter-Fed AC Machine Drive System," Power Electronics, IEEE Transactions on, vol.28, no.3, pp.1366,1381, March 2013.

[4] Gui-Jia Su; Lixin Tang, "Current source inverter based traction drive for EV battery charging applications," Vehicle Power and Propulsion Conference (VPPC), 2011 IEEE, vol., no., pp.1,6, 6-9 Sept. 2011.

[5] A. Azmi, G. P. Adam and B. W. Williams, "New modulation strategy for three-phase current source inverters," Power Engineering, Energy and Electrical Drives (POWERENG), 2013 Fourth International Conference on, Istanbul, 2013, pp. 1110-1115.

[6] P. Saranya and V. Rajini, "Selective harmonic elimination in three-phase Current Source Inverter- A generalized approach," Emerging Trends in Electrical and Computer Technology (ICETECT), 2011 International Conference on, Tamil Nadu, 2011, pp. 358-363.

[7] M. Lakka, E. Koutroulis and A. Dollas, "Development of an FPGA-Based SPWM Generator for High Switching Frequency DC/AC Inverters," in IEEE Transactions on Power Electronics, vol. 29, no. 1, pp. 356-365, Jan. 2014.

[8] Adamowicz, M.; Morawiec, M., "Advances in CSI-fed induction motor drives," in Compatibility and Power Electronics (CPE), 2011 7th International ConferenceWorkshop, vol., no., pp.276-282, 1-3 June 2011.

[9] Qin Lei; Fang Zheng Peng, "Space Vector Pulsewidth Amplitude Modulation for a Buck-Boost Voltage/Current Source Inverter," in Power Electronics, IEEE Transactions on, vol.29, no.1, pp.266-274, Jan. 2014T 